\title{
DESENVOLVIMENTO DE COMPETÊNCIAS EM INSTITUIÇÕES PÚBLICAS DE ENSINO SUPERIOR: UM ESTUDO COMPARATIVO NAS MODALIDADES À DISTÂNCIA E PRESENCIAL
}

\author{
Lilian Ferrugini $^{2}$ \\ Cleber Carvalho Castro $^{3}$ \\ Donizeti Leandro Souza ${ }^{4}$ \\ Raphael Morais ${ }^{5}$
}

Resumo: Identifica-se que as pessoas estão em constante busca pelo desenvolvimento e rendimento de competências diversas para se manterem atuantes no mercado de trabalho. Nesse sentido, o estudo teve o objetivo de identificar, a partir da percepção de alunos, o desenvolvimento de competências nas modalidades de educação à distância e presencial de cursos de Administração em instituições públicas de ensino superior. $O$ estudo se mostra relevante por ampliar o debate sobre competências desenvolvidas no meio acadêmico na área de Administração e áreas afins como contabilidade e economia, o que permite analisar se está havendo um alinhamento entre o discurso das competências demandadas pelo mercado com as práticas desenvolvidas durante o processo de formação acadêmica, tanto em cursos presenciais como à distância. Para tanto, realizou-se uma pesquisa quantitativa, a partir de um survey com 211 alunos pesquisados nas duas modalidades educacionais. Identificou-se que nos cursos presenciais as competências mais desenvolvidas foram: capacidade de interpretar textos, gráficos, símbolos e números e capacidade de cooperação e trabalho em equipe. Nos cursos à distância foram: visão de mundo ampla e global e capacidade de lidar com incertezas e dúvidas, demonstrando haver diferenças na formação acadêmica dos alunos.

Palavras-chave: Desenvolvimento de Competências; Instituições Públicas de Ensino Superior; Curso Superior Presencial; Curso Superior à Distância.

\footnotetext{
O artigo foi publicado nos anais do congresso - XVII SemeAd (Seminários em Administração - FEA-USP) de 29 a 31 de outubro de 2014

2E-mail: lilianuff@yahoo.com.br. - . Instituto Federal de Educaçăo, Ciência e Tecnologia do Sul de Minas Gerais

${ }^{3}$ E-mail: clebercastro@dae.ufla.br. - Universidade Federal de Lavras.

E-mail: souza.doni@yahoo.com.br. - Instituto Federal de Educação, Ciência e Tecnologia do Sul de Minas Gerais

E-mail: raphaelmoraisufla@gmail.com. - Universidade Federal de Lavras 


\title{
COMPETENCIES DEVELOPMENT IN PUBLIC INSTITUTIONS OF HIGHER EDUCATION: A COMPARATIVE STUDY IN DISTANCE AND PRESENTIAL MODALITIES
}

\begin{abstract}
People are in constant searching for the development and performance of various competencies to remain themselves active in the labor market. In this sense, this study aimed to identify the development of competencies in distance and presential education modalities of Administration courses in public institutions of higher education, through the perception of students. This study is relevant because it broadens the debate on competencies developed in scientific academy in the area of Administration and related fields such as accounting and economics, which allows to analyze if there is an alignment between the speech of the demanded competencies by the market and the practices developed during the process of academic education, in both distance and presential modalities. To this end, we carried out a quantitative research, based on a survey of 211 students in both educational modalities. It was identified that in the presential courses the ability to interpret text, graphics, symbols and numbers and capacity of cooperation and teamwork were the most developed competencies. In distance modality, wide and global worldview and ability to cope with uncertainty and doubt were the most developed competencies. These results show the existence of differences in academic formation of the students.
\end{abstract}

Keywords: Development of Competencies; Public Institutions of Higher Education; Distance Higher Education Course; Presential Higher Education Course. 


\section{INTRODUÇÃO}

$\mathrm{D}$ iversos estudiosos e especialistas concordam que lidar com os desafios da atual sociedade do conhecimento requer um melhor desenvolvimento de habilidades complexas que vão muito além da simples reprodução do conhecimento acumulado. Estes desafios têm exigido a mobilização de aptidões cognitivas e práticas, habilidades criativas e outros recursos psicossociais como atitudes, motivações e valores necessários ao desenvolvimento de novas competências.

Grande parte da literatura sobre competências tem centrado suas discussões na perspectiva organizacional, destacando a necessidade de indivíduos ou empresas desenvolverem competências centrais para acompanhar as exigências do mercado. Porém, pouco se tem debatido sobre o papel das instituições de ensino superior (IES) no desenvolvimento dessas e outras competências para uma vida de sucesso. Surge, assim, a necessidade de novas discussões sobre o papel da academia em permitir aos alunos, não apenas adquirir e gerar conhecimentos, mas refletir e mobilizar uma complexidade de comportamentos e decisões ligadas a uma vida sustentável, seja no âmbito profissional, pessoal ou social, colocando os objetivos educacionais em metas globais para o desenvolvimento de uma aprendizagem contínua ao longo da vida (Baartman \& Ruijs, 2011; Barth, Godemann, Rieckmann \& Stoltenberg, 2007; Rychen \& Salganik, 2005; OECD, 2001).

Dessa forma, identifica-se que as pessoas têm se deparado com a necessidade de aprimoramento e especialização de sua força de trabalho (Huh, Jongdae, Lee \& Yoo, 2010; Nunes, 2009) e estão em constante busca pelo desenvolvimento e rendimento de competências diversas para se manterem atuantes no mercado, algo que, em parte, pode ser conquistado por meio de cursos superiores presenciais ou à distância, acarretando numa mão de obra qualificada, criativa e com capacidade inovadora (Tudorescu, Zaharia, Zaharia \& Zaharia, 2010), ao mesmo tempo que permite uma formação para situações complexas, em que o indivíduo seja capaz de agir de forma autônoma e tomar decisões dinâmicas e efetivas (Barth et al., 2007; Rychen \& Salganik, 2005).

Neste contexto, alguns questionamentos instigam a elaboração da pesquisa: Quais práticas educacionais, no que se refere as competências demandadas pelo mercado, têm sido desenvolvidas pelas Instituições públicas de Ensino superior? Existem perspectivas de formação diferentes entre cursos presencias e a distância? Essas questões se mostram relevantes, pois colocam a academia no centro de dois grandes desafios: (a) consolidar um sistema de ensino abrangente que permita o desenvolvimento máximo das capacidades humanas e (b) promover uma formação ampla que contemple competências essenciais para uma vida de sucesso (Pons, 2010).

Assim, o objetivo deste artigo é identificar, a partir da percepção de alunos, o desenvolvimento de competências nas modalidades à distância e presencial em instituições públicas de ensino superior, comparando níveis de percepções e gargalos de formação em cursos de bacharelado em Administração.

O estudo se mostra relevante por ampliar o debate sobre competências desenvolvidas no meio acadêmico dos cursos de Administração e áreas afins, o que permite analisar se está havendo um alinhamento entre o discurso das competências demandadas pelo mercado com as práticas desenvolvidas durante o processo de formação acadêmica, tanto em cursos presenciais como à distância. Além disso, o 
estudo pode contribuir para avaliar e questionar os tradicionais modelos de currículos, considerando a formação de competências como algo que transcende a qualificação técnica, visando outras habilidades necessárias a uma formação sistêmica.

\section{DESENVOLVIMENTO DE COMPETÊNCIAS NO AMBIENTE ACADÊMICO}

A literatura sobre o estudo de competências tem se concentrado em duas importantes correntes de pensamento: a abordagem americana, na qual competências são concebidas como um conjunto mensurável de conhecimentos, habilidades e atitudes associados ao desempenho de tarefas ou cargos; e a abordagem francesa, reconhecendo competências como a mobilização de habilidades múltiplas em ambientes organizacionais cada vez mais mutáveis e complexos (Le Boterf, 2003; Fleury \& Fleury, 2001; Perrenoud, 2001; Zarifian, 2001; Spencer \& Spencer, 1993; Boyatzis, 1982; Mcclelland, 1973).

Nos últimos anos, percebe-se que a educação tem assumido um papel decisivo nas agendas internacionais, transcendendo funções meramente cognitivas para novas perspectivas econômicas, sociais e políticas no desenvolvimento das nações. Frente a essas questões, tem emergido no âmbito acadêmico estudos sobre competências, numa abordagem educacional em debates sobre o papel das IES na formação de competências gerais capazes de preparar o indivíduo para as novas exigências da sociedade (Lozano et al., 2012; Young, 2010; Godoy \& Antonello, 2009; Mulder et al. 2009; Valimaa \& Hoffman, 2008; Bleiklie, 2005; Rychen \& Salganik, 2005; Istance, 2003; OECD, 2001; Holmes \& Hooper, 2000).

Segundo Weinert (1999) ao longo das últimas décadas uma grande atenção científica internacional tem sido dada à construção de "competências-chave", capazes de preparar os indivíduos para dominar diferentes demandas. Definir essas competências-chave durante o processo de formação acadêmica seria as preocupações centrais nos processos de ensino-aprendizagem, pois se poderiam melhorar as avaliações do quão bem preparados jovens e adultos estão para os desafios da vida, bem como identificar as metas globais para os sistemas de educação e aprendizagem (Rychen \& Salganik, 2005).

Sob esta perspectiva, o estudo de competências tem assumido bases epistemológicas sistêmicas, pois competências passam a ser definidas como um conjunto de habilidades-chave necessárias ao bom funcionamento da sociedade, transcendendo as perspectivas tradicionais (americana e francesa) ao focar a formação de indivíduos para uma vida econômica e social sustentável (Rychen \& Salganik, 2005; Fleury \& Fleury, 2001; OECD, 2001).

A busca pelas competências-chave tem sido motivada por duas preocupações principais: (a) a hipótese de que as competências adquiridas nos ambientes acadêmicos e profissionais são desenvolvidas e mobilizadas de formas específicas no mercado de trabalho e na sociedade e (b) que a maioria das atividades ao longo da vida ocorre em uma variedade de contextos sociais e profissionais. Isso tem levado à busca pela definição das competências necessárias às diferentes demandas sociais e contextos organizacionais. Para muitos estudiosos, a questão central é saber quais são e como podem ser desenvolvidas essas competências nos programas de ensino (Weinert, 1999).

A pergunta a se fazer não está em compreender como a competência é definida, mas em como ela pode ser mobilizada em situações particulares, pois a verdadeira manifestação da competência estabelece a sua existência. Uma questão igualmente difícil é a necessidade de definir as competências necessárias para o mercado de trabalho, para as relações sociais e para as demandas pessoais futuras, pois o indivíduo deve ser capaz de ser um trabalhador, um membro da família, um cidadão na comunidade e assim por diante (Ouane, 2003). Acrescentando essa discussão, os alunos devem ser preparados para o mercado 
de trabalho, ou seja, devem ser capacitados para atuarem como colaboradores e gestores de empresas, assim como donos de seus próprios negócios.

Assim, diversos estudos sobre competências e sua relação com o ambiente acadêmico têm surgido na academia, buscando investigar o papel das instituições de ensino no desenvolvimento de competências-chave. Entre as principais iniciativas internacionais destacam-se: o "Processo de Bolonha”, um espaço de discussão com vista a reformar as estruturas dos sistemas de ensino superior europeu; o Projeto Tuning, realizado por um consórcio de universidades europeias e latino-americanas e o Projeto DeSeCo (Definição e Seleção de Competências-chave), patrocinado pela Organização para a Cooperação e Desenvolvimento Econômico (Lozano, Boni, Peris \& Hueso, 2012; Beneitone et al., 2007).

Segundo Lozano et al. (2012) e Gilomen (2003), o Projeto DeSeCo é um dos estudos mais abrangentes e detalhados sobre competências-chave no ambiente acadêmico, além de ser amplamente reconhecido e utilizado em todo o mundo nas avaliações da educação básica e do ensino superior. Por este motivo discutiremos na seção seguinte as principais características e iniciativas do Projeto DeSeCo e sua relação com o desenvolvimento de competências no ambiente acadêmico.

\subsection{PROJETO DESECO E A BUSCA PELAS COMPETÊNCIAS-CHAVE}

Ao longo de sua breve história, o Projeto DeSeCo tem procurado incluir uma ampla gama de perspectivas, não só da comunidade acadêmica, mas da política pública, do trabalho, da educação e dos setores empresariais. Esse projeto reuniu inúmeros especialistas, políticos, sindicalistas e demais profissionais com o objetivo de promover um debate sobre um entendimento comum das "competências-chave para o século XXI". Nesse debate a Organização para a Cooperação e Desenvolvimento Econômico (OCDE) tem assumido um papel relevante nas agendas internacionais, estabelecendo um marco sobre quais competências básicas são esperadas dos jovens e adultos no mundo moderno, além de definir quais competências devem ser desenvolvidas com a escolaridade para enfrentar os novos desafios socioeconômicos (Rychen \& Salganik, 2005).

Seguindo alguns conceitos da abordagem francesa, os idealizadores do Projeto DeSeCo reconhecem que as competências envolvem a capacidade de atender demandas complexas por meio da mobilização de recursos psicossociais em contextos particulares. Segundo seus idealizadores, o contexto define o conteúdo da competência, pois, os indivíduos são competentes quando têm potencial para resolver problemas frente à complexidade de situações específicas. O mais importante para essa conceituação é a noção que as competências se manifestam em ações, comportamentos e decisões em contextos particulares (Chizzotti \& Casali, 2012; Lozano et al., 2012; Gilomen, 2003; Ouane, 2003).

O Projeto DeSeCo procura, em colaboração com programas de avaliação da OCDE, analisar a fundamentação teórica, a lógica das definições e o processo de seleção de competências-chave e suas relações com o ambiente socioeconômico. Além disso, tem como objetivo fornecer orientações para o trabalho, no desenvolvimento de amplas competências humanas no contexto internacional (Gilomen, 2003; OECD, 2001).

Segundo Rychen e Salganik (2005), a estrutura conceitual do Projeto DeSeCo define nove competências-chave, classificadas em três grandes categorias de formação educacional, são elas: a) Uso das ferramentas de forma interativa: (i) habilidade de usar linguagem, símbolos e textos de forma interativa; (ii) capacidade de usar conhecimentos e informações de forma interativa e (iii) capacidade de usar a tecnologia; b)Interação em grupos heterogêneos: (i) capacidade de interagir bem com os outros; 
(ii) capacidade de cooperação e (iii) capacidade de gerir e resolver conflitos; c) Atuação de maneira autônoma: (i) capacidade de agir dentro da sociedade; (ii) capacidade de formar e conduzir planos de vida e projetos pessoais e (iii) capacidade de fazer valer os direitos, interesses, limites e necessidades.

A definição dessas competências tem como missão fornecer bases conceituais para um quadro global de referências que podem estruturar um consenso abrangente de competências socialmente valorizadas. As competências-chave partilham uma série de características que implicam o desenvolvimento do pensamento crítico e da abordagem reflexiva, beneficiando tanto o indivíduo como a sociedade em geral (Lozano et al., 2012; Rychen \& Salganik, 2005). Uma das preocupações centrais do projeto DeSeCo tem sido resgatar o papel da educação superior para dar uma resposta aos desafios enunciados, assumindo como funções principais o desenvolvimento de competências para uma reorientação dos processos de ensino-aprendizagem. Além da formação profissional, a educação superior deve permitir uma formação para situações complexas, em que o indivíduo seja capaz de agir de forma autônoma e tomar decisões dinâmicas e efetivas (Barth et al., 2007; Rychen \& Salganik, 2005).

\subsection{EVIDÊNCIAS EMPÍRICAS NO CONTEXTO BRASILEIRO}

No Brasil, os estudos sobre competências no ambiente acadêmico têm ocupado espaços privilegiados para novas perspectivas pedagógicas voltadas à implementação de reformas educacionais (Nunes, 2010). Um desses estudos foi realizado por Sant'Anna (2002), o qual investigou, a partir da opinião de alunos, até que ponto a demanda pelas competências individuais requeridas pelo mercado tem sido acompanhada por uma modernidade de políticas e práticas de gestão capaz de propiciar um ambiente organizacional.

Através de uma extensa revisão bibliográfica, em autores das abordagens americana e francesa, Sant'Anna (2002) identificou um conjunto de quinze competências profissionais centrais, são elas: (1) domínio de novos conhecimentos técnicos associados ao exercício do cargo ou função; (2) capacidade de aprender rapidamente novos conceitos e tecnologias; (3) criatividade; (4) capacidade de inovação; (5) capacidade de comunicação; (6) capacidade de relacionamento interpessoal; (7) capacidade de trabalho em equipe; (8) autocontrole emocional; (9) visão de mundo ampla e global; (10) capacidade de lidar com situações novas e inusitadas; (11) capacidade de lidar com incertezas e ambiguidades; (12) iniciativa de ação e decisão; (13) capacidade de comprometer-se com os objetivos da organização; (14) capacidade de gerar resultados efetivos e (15) capacidade empreendedora.

Apesar de não focar diretamente no desenvolvimento de competências no ambiente educacional, este estudo foi útil para identificar que as competências profissionais requeridas pelo mercado não tem sido acompanhada, em mesmo nível, por uma modernidade de políticas e práticas de gestão, surgindo a necessidade de ambientes organizacionais mais aderentes aos novos perfis profissionais requeridos (Sant'Anna, 2002).

Souza, Corrêa, Sousa e Zambalde (2013), tendo como referência o conjunto de competências proposto por Sant'Anna (2002), identificaram, por meio de técnicas estatísticas multivariadas e descritivas, limitações no desenvolvimento de competências empreendedoras, surgindo a necessidade das IES estimularem à criatividade e o preparo de alunos para lidarem com situações de incerteza e dúvidas frente às atuais exigências do cenário organizacional.

Outro estudo relevante foi realizado por Brasil (2009), o qual realizou um estudo prospectivo das competências profissionais e organizacionais para investigar se os programas de educação superior atendem as demandas do mercado. Os resultados indicaram que as competências de liderança, mo- 
tivação e comunicação seriam as mais complexas e imprescindíveis no contexto das organizações, surgindo a necessidade de um planejamento das atividades de negociação, legislação, finanças, orçamento, logística e mercado global.

Já Nogueira e Bastos (2012) analisaram a percepção das competências docentes por meio da visão de professores e alunos de uma universidade privada, tendo como objetivo, identificar, junto aos docentes, as competências necessárias nos processos de ensino-aprendizagem e, posteriormente, identificar como estas competências são percebidas por discentes concluintes em cursos de bacharelado em Administração.

Conforme apresentado na Figura 1, diversos estudos podem ser identificados no contexto brasileiro, assumindo abordagens empíricas específicas sobre as competências demandadas pelo mercado e o papel das IES no desenvolvimento das mesmas.

\begin{tabular}{|c|c|}
\hline Principais estudos & Foco central \\
\hline Godoy et al. (2009); Godoy e Antonello (2009); Souza (2014). & $\begin{array}{c}\text { Competências específicas à formação do } \\
\text { administrador. }\end{array}$ \\
\hline $\begin{array}{c}\text { Souza et al. (2013); Vazquez e Ruas (2012); Brasil (2009); } \\
\text { Sant'Anna (2002). }\end{array}$ & Desenvolvimento de competências profiss ionais. \\
\hline $\begin{array}{c}\text { Odelius e Sena (2009); Teixeira, Vitcel e Lampert (2008) } \\
\text { Nogueira e Bastos (2012); Nunes e Patrus-Pena (2011); Nunes } \\
\text { (2010); Nunes e Barbosa (2009); Quel (2008); Paiva (2007); } \\
\text { Paiva, Esther e Melo (2004) }\end{array}$ & $\begin{array}{c}\text { Desenvolvimento de competências comunicativas } \\
\text { e de investigação científica. }\end{array}$ \\
\hline $\begin{array}{c}\text { Compentias ao desentes e práticas pedagógicas } \\
\text { no ambiente acadêmico de competências }\end{array}$ \\
\hline
\end{tabular}

Figura 1: Síntese de evidências empíricas no contexto brasileiros Fonte: Adaptado de Souza, D. L. (2014) Desenvolvimento de competências e ambiente acadêmico: Um estudo em cursos de Administração (Dissertação de Mestrado). Universidade Federal de Lavras, Lavras, MG, Brasil.

Apesar dos recentes avanços dos estudos brasileiros sobre a relação de desenvolvimento de competências e ambiente acadêmico, Godoy e Antonello (2009) asseveram que os estudos na educação superior ainda carecem de aprofundamentos, o que dificulta a sua utilização na organização dos projetos pedagógicos e apresenta dificuldades no desenvolvimento das competências-chave demandadas pelo mercado. Assim, faz necessário ampliar as discussões sobre o desenvolvimento de competências no ambiente acadêmico, buscando explorar novas abordagens metodológicas capazes de avaliar se os discursos, nas diferentes modalidades de educação, têm sido reconhecidos na percepção dos alunos.

\section{PROCEDIMENTOS METODOLÓGICOS}

O estudo se baseia na abordagem quantitativa e pesquisa de campo, sendo utilizada para a coleta de dados a técnica survey, por permitir coletar informações sistemáticas e padronizadas sobre a avaliação de opiniões, conhecimentos, atitudes e comportamentos de um grande contingente de pessoas (Taylor-Power \& Hermann, 2000).

Trata-se de uma pesquisa descritiva, uma vez que se buscou identificar a frequência e as características mais representativas nas percepções dos respondentes, tanto em relação ao perfil da amostra, como em relação aos diferentes graus de competências desenvolvidas durante o período de formação 
acadêmica (Vergara, 2005). A pesquisa foi realizada junto a uma amostra não probabilística e por conveniência com alunos de cursos de Bacharelado em Administração em instituições públicas de ensino superior, com oferta nas modalidades presencial e a distância.

Para os alunos de cursos à distância, a amostra foi composta por alunos egressos do curso piloto de Administração, ofertado pelo sistema Universidade Aberta do Brasil. Após contato com as instituições participantes, foi enviado, via Google docs ${ }^{\circledR}$, o questionário contendo questões demográficas e preditoras a 2.652 alunos, localizados em diversas regiões do Brasil. Deste total, obteve-se 102 questionários respondidos. Para os alunos de cursos presenciais, o mesmo questionário foi aplicado pessoalmente com os alunos concluintes de cursos de Administração em duas universidades federais de Minas Gerais. Nesta etapa obteve-se um total de 109 questionários preenchidos. A amostra final correspondeu a 211 respondentes. Os questionários foram aplicados entre os meses de agosto a outubro de 2014

Cabe destacar que anterior à aplicação dos questionários foi realizada a fase de pré-teste com o propósito de testar as escalas e verificar os possíveis problemas de compreensão, duração e sequência das questões. Assim, foi aplicado junto aos alunos do $3^{\circ}$ ano dos cursos de bacharelado em Administração de 2 (duas) IES públicas de Minas Gerais trinta questionários como etapa de pré-teste. Nesta fase foi solicitado que os respondentes comentassem as possíveis dificuldades de entendimento, sequência das questões e sugestões de melhoria, obtendo, ao final, um retorno de 23 questionários respondidos corretamente.

O levantamento de dados foi composto por questionários estruturados, divididos em duas seções principais: a seção I composta por questões demográficas (categóricas), com o propósito de caracterizar o perfil dos respondentes; e a seção Il composta por questões preditoras construída a partir de categorias comuns entre as competências individuais requeridas (Sant'Anna, 2002) e as competências-chave propostas pelo projeto DeSeCo (Rychen \& Salganik, 2005) para avaliar em que medida tais competências têm sido desenvolvidas em cursos presenciais e à distância.

Para análise foi utilizada a análise descritiva dos dados para descrever o perfil da amostra, assim como as competências mais e/ou menos desenvolvidas. Em seguida utilizou-se a análise de variância (ANOVA) com a finalidade de avaliar se os grupos de respondentes (modalidade à distância e presencial) diferem entre si. Posteriormente, procedeu-se a análise discriminante com o propósito de verificar quais variáveis (competências) melhor discriminam os grupos (Hair Jr. et al., 2009).

Ademais, cabe ressaltar que a coleta de dados se deu por meio de escalas tipo Likert, variando de 0 (não desenvolvido) a 10 (fortemente desenvolvido), sendo utilizado o pacote estatístico SPSS ${ }^{\circledR}$ para análise descritiva e multivariada dos dados.

\section{RESULTADOS}

A análise dos resultados deu-se a partir de duas seções principais. Na primeira seção é apresentado, por meio da estatística descritiva, o perfil dos respondentes, visando estimar as características da amostra e calcular em que medida as competências estão sendo desenvolvidas em cursos nas modalidades à distância e presencial. Na segunda seção é realizada a análise dos dados através da análise de variância (ANOVA) e da análise discriminante, buscando identificar quais competências melhor discriminam os perfis de formação acadêmica nas modalidades à distância e presencial. 


\subsection{DESENVOLVIMENTO DE COMPETÊNCIAS EM CURSOS PRESENCIAIS}

Em relação ao perfil dos respondentes de cursos presenciais, percebe-se que a maioria é formada por alunos do sexo feminino (52,3\%), com faixa etária entre 21 a 25 anos (89\%) e solteiros (98,2\%). Sobre o local onde cursaram o ensino médio, $78 \%$ dos pesquisados são egressos de escolas privadas e quando questionados sobre o motivo pela escolha do curso de Administração, o interesse pela área administrativa (62\%) e a falta de opção $(24,1 \%)$ foram as motivações predominantes. Quando questionados sobre a experiência profissional, apenas $9,2 \%$ dos pesquisados afirmaram atuar na área a mais de 3 anos e 36,7\% afirmaram não estar atuando na área no momento da pesquisa. Entre os que já possuíam algum tipo de experiência profissional, o setor de serviços $(40,7 \%)$ e a indústria $(38,5 \%)$ foram os setores com as maiores frequências de respostas.

Em relação às competências mais desenvolvidas, destacam-se a capacidade de cooperação e trabaIho em equipe $(8,85)$, o comprometimento e responsabilidade $(8,46)$ e a capacidade de comunicação e uso da linguagem escrita e falada $(8,35)$ com as maiores médias na percepção dos pesquisados. Entre as competências menos desenvolvidas, destacam-se capacidade de investigação científica $(6,01)$, a capacidade de inovação $(6,35)$ e a criatividade $(6,40)$, conforme apresentado na Tabela 1 .

Tabela 1: Média das Competências Gerais Desenvolvidas nos cursos presenciais

\begin{tabular}{|l|c|c|}
\hline \multicolumn{1}{|c|}{ Competências } & Média & Desvio padrão \\
\hline Capacidade de cooperação e trabalho em equipe & 8,85 & 1,69 \\
\hline Comprometimento e responsabilidade & 8,46 & 1,89 \\
\hline Capacidade de comunicação e uso da linguagem escrita e falada & 8,35 & 1,93 \\
\hline Capacidade de interpretar textos, gráicos, símbolos e números & 8,30 & 1,66 \\
\hline Capacidade de relacionamento interpessoal & 8,23 & 2,19 \\
\hline Iniciativa de ação e decisão & 7,75 & 2,07 \\
\hline Capacidade de gerar resultados efetivos & 7,50 & 1,98 \\
\hline Capacidade de resolver conflitos & 7,39 & 1,99 \\
\hline Formação cidadã crítica (reconhecer direitos e deveres) & 7,29 & 2,43 \\
\hline Planejar e conduzir planos de vida e projetos pessoais & 7,18 & 2,62 \\
\hline Visão de mundo ampla e global & 7,16 & 1,97 \\
\hline Capacidade de aprender e aplicar novos conceitos e tecnologias & 7,09 & 2,11 \\
\hline Capacidade empreendedora & 7,09 & 2,56 \\
\hline Capacidade de lidar com situações novas e inusitadas & 6,93 & 2,14 \\
\hline Domínio de novos conhecimentos técnicos ligados à profissão & 6,90 & 2,09 \\
\hline Autocontrole emocional & 6,86 & 2,62 \\
\hline Capacidade de lidar com incertezas e dúvidas & 6,67 & 2,28 \\
\hline Criatividade & 6,40 & 2,24 \\
\hline Capacidade de inovação & 2,14 \\
\hline Investigação científica & 2,99 \\
\hline Escore médio & 7,34 \\
\hline
\end{tabular}

Fonte: Dados da pesquisa

Ademais, os valores de desvio-padrão indicam a variabilidade de percepções entre os respondentes e a média geral sobre o desenvolvimento das competências representa um escore de 7,34, indicando 
que as competências gerais demandas pela literatura (Rychen \& Salganik, 2005; Sant'Anna, 2002) têm sido parcialmente desenvolvidas nos cursos de Administração presencial pesquisados.

\subsection{DESENVOLVIMENTO DE COMPETÊNCIAS EM CURSOS A DISTÂNCIA}

Em relação ao perfil dos respondentes dos cursos à distância, percebe-se que a maioria é formada por estudantes do sexo masculino (54\%), com faixa etária acima de 40 anos (73,5\%) e casados (77,5\%). Sobre o local onde cursaram o ensino médio, $72 \%$ dos pesquisados são egressos de escolas públicas e quando questionados sobre o motivo pela escolha do curso de Administração, a ascensão profissional (52\%) e o interesse pela área (39,2\%) foram as motivações predominantes. Em relação à experiência profissional, a maioria dos respondentes $(77,5 \%)$ afirmou atuar na área a mais de três anos e a maioria no setor público $(63,7 \%)$.

Em relação às competências mais desenvolvidas, destacam-se o comprometimento e responsabilidade $(8,50)$, a capacidade de cooperação e trabalho em equipe $(8,04)$ e a visão de mundo ampla e global $(8,04)$ com as maiores médias de percepções. Entre as competências menos desenvolvidas, destacam-se a capacidade de investigação científica $(6,62)$, a capacidade empreendedora $(7,11)$ e o autocontrole emocional $(7,18)$, conforme apresentado na Tabela 2.

Tabela 2: Média das Competências Gerais Desenvolvidas em cursos à distância.

\begin{tabular}{|c|c|c|}
\hline Competências Gerais & Média & Desvio padrão \\
\hline Comprometimento e responsabilidade & 8,50 & 1,62 \\
\hline Capacidade de cooperação e trabalho em equipe & 8,04 & 1,71 \\
\hline Visão de mundo ampla e global & 8,04 & 1,67 \\
\hline Iniciativa de ação e decisão & 7,97 & 1,75 \\
\hline Capacidade de comunicação e uso da linguagem escrita e falada & 7,94 & 1,67 \\
\hline Formação cidadã crítica (reconhecer direitos e deveres) & 7,92 & 2,14 \\
\hline Capacidade de relacionamento interpessoal & 7,87 & 1,74 \\
\hline Domínio de novos conhecimentos técnicos ligados à profissão & 7,84 & 1,93 \\
\hline Capacidade de aprender e aplicar novos conceitos e tecnologias & 7,70 & 1,78 \\
\hline Planejar e conduzir planos de vida e projetos pessoais. & 7,70 & 2,04 \\
\hline Capacidade de gerar resultados efetivos & 7,65 & 1,61 \\
\hline Capacidade de lidar com situações novas e inusitadas & 7,65 & 2,02 \\
\hline Capacidade de lidar com incertezas e dúvidas & 7,40 & 1,79 \\
\hline Capacidade de interpretar textos, gráficos, símbolos e números & 7,40 & 2,22 \\
\hline Capacidade de inovação & 7,38 & 2,03 \\
\hline Capacidade de resolver conflitos & 7,35 & 2,05 \\
\hline Criatividade & 7,21 & 1,94 \\
\hline Autocontrole emocional & 7,18 & 2,30 \\
\hline Capacidade empreendedora & 7,11 & 2,07 \\
\hline Investigação científica & 6,62 & 2,30 \\
\hline Média geral & \multicolumn{2}{|c|}{7,62} \\
\hline
\end{tabular}

Fonte: Dados da pesquisa 
Ademais, os valores de desvio-padrão indicam a variabilidade de percepções entre os respondentes e a média geral sobre o desenvolvimento das competências representa um escore médio de 7,62, valor levemente superior se comparado à percepção dos respondentes egressos dos cursos presenciais.

\subsection{COMPARATIVO ENTRE CURSOS À DISTÂNCIA E PRESENCIAIS}

Com relação ao perfil da amostra, percebe-se uma grande variação nas características dos respondentes. Dentre elas, percebe-se que os cursos presenciais são formados por alunos, em sua maioria, jovens, solteiros, egressos de ensino médio de instituições particulares e com pouca experiência na atividade profissional, tendo optado pelo curso devido ao interesse pela área administrativa. Já os cursos à distância são formados por alunos, em sua maioria, adultos, casados, egressos do ensino médio de instituições públicas e com alta experiência na atividade profissional, tendo optado pelo curso de Administração para ascensão profissional.

Tais resultados corroboram os estudos de Moore e Kearsley (2011) e Nunes (2009) os quais asseveram sobre a existência de perfis demográficos diferentes entre alunos de cursos na modalidade à distância se comparado ao perfil dos alunos de cursos presenciais. Nesta modalidade os alunos ainda estão em fase de maturidade e de pouca experiência profissional, o que de certa forma pode contribuir para que eles mudem de curso ao perceberem a essência dos conteúdos ministrados. Já o perfil dos alunos da modalidade a distância os fazem escolher e permanecer no curso por já estarem inseridos no mercado de trabalho, apesar da taxa de evasão ainda ser muito grande, ocorrendo por motivos diversos, e não devido aos conteúdos ministrados.

Em relação às percepções médias sobre o desenvolvimento das competências gerais, utilizou-se a análise de variância (ANOVA) para verificar se existem diferenças significativas entre as médias atribuídas pelos respondentes. $O$ teste de igualdade das médias indicou que o desenvolvimento de dez competências se mostra diferente entres os grupos investigados, sendo estas competências, significativas a $5 \%$ pelo teste F, conforme apresentado na Tabela 3.

Tabela 3: Testes de igualdade de médias

\begin{tabular}{|l|c|c|}
\hline \multicolumn{1}{|c|}{ Competências } & F & Sig. \\
\hline Capacidade de inovação & 12,516 & 0,0005 \\
\hline Capacidade de cooperação e trabalho em equipe & 11,830 & 0,0007 \\
\hline Visão de mundo ampla e global & 11,520 & 0,0008 \\
\hline Domínio de novos conhecimentos técnicos ligados à profissão & 11,413 & 0,0009 \\
\hline Capacidade de interpretar textos, gráficos, símbolos e números & 11,116 & 0,0010 \\
\hline Criatividade & 7,647 & 0,0062 \\
\hline Capacidade de lidar com situações novas e inusitadas & 6,275 & 0,0130 \\
\hline Capacidade de lidar com incertezas e dúvidas & 6,019 & 0,0150 \\
\hline Capacidade de aprender e aplicar novos conceitos e tecnologias & 5,071 & 0,0254 \\
\hline Formação cidadã crítica (reconhecer direitos e deveres) & 3,890 & 0,0499 \\
\hline
\end{tabular}

Fonte: Dados da pesquisa

Nas demais variáveis, os testes $F$ não rejeitaram a hipótese nula de que as médias entre os grupos são semelhantes, indicando que essas competências sofreram pouca variação média na percepção dos alunos, não representando, estatisticamente, diferenças significativas de percepções entre os grupos de respondentes. 
Apesar de identificar diferentes escores médios sobre o desenvolvimento de competências gerais entre estudantes de cursos à distância e presencial, percebe-se pelas Tabelas 1 e 2 certa similaridade de respostas pelas ordens de percepções sobre as competências mais e/ou menos desenvolvidas durante o período de formação acadêmica. No grupo das competências mais desenvolvidas, merece destaque o comprometimento e responsabilidade e a capacidade de cooperação e trabalho em equipe, representando as competências mais desenvolvidas em ambos os grupos. Estes resultados corroboram os estudos de Sant'Anna (2002) o qual identificou que as competências mais demandas pelas organizações têm sido a capacidade de comprometimento e responsabilidade, relacionamento interpessoal, trabalho em equipe e capacidade de comunicação, indicando que nos cursos pesquisados têm sido desenvolvidas melhor as competências reconhecidas como as mais demandadas pelo mercado.

No grupo das competências menos desenvolvidas, a capacidade de investigação científica foi a competência com o menor escore médio identificado, tanto nos cursos presenciais como a distância. $\mathrm{O}$ baixo nível de desenvolvimento dessa competência torna-se algo preocupante, pois Odelius e Sena (2009) afirmam que o contato com as atividades de investigação científica oportuniza o desenvolvimento de competências complementares, tais como: (a) relacionamento interpessoal; (b) competências técnicas de leitura e interpretação de textos; (c) habilidades de comunicação e redação de textos científicos; (d) comportamentos e atitudes, como disciplina, ética, proatividade e raciocínio lógico; (e) processamento de dados e (f) aspectos gerenciais como visão estratégica e sistêmica.

Destacam-se, também, as baixas percepções das competências relacionadas à capacidade empreendedora, criatividade e inovação, corroborando os estudos de Souza et al. (2013) e Mello, Melo e Mattar (2011), os quais identificaram que o conjunto de competências empreendedoras tem sido pouco desenvolvido em cursos de Administração, surgindo a necessidade das IES desenvolverem melhor essas competências, uma vez que a atuação do administrador tem sido reconhecida como uma profissão que exige visão sistêmica, surgindo a preocupação para o desenvolvimento de novos empreendedores com criatividade e inovação, a fim de fomentar o avanço tecnológico no país.

Além disso, a educação superior deve permitir uma formação para situações complexas, em que o indivíduo seja capaz de agir de forma autônoma e tomar decisões dinâmicas e efetivas (Barth et al., 2007; Rychen \& Salganik, 2005).

Tendo em vista, as divergências e similaridades de respostas, o estudo foi complementado pela análise discriminante, que segundo Hair Jr et al. (2009) permite prever e explicar relações que melhor discriminam objetos em grupos pré-definidos. A análise discriminante também pode ser apropriada para testar hipóteses de que as médias de grupos de um conjunto de variáveis independentes para dois ou mais grupos são iguais, permitindo uma comparação do quão afastados estão os grupos em termos da função discriminante (Hair Jr., 2009). Na Tabela 4 são apresentados os resultados da análise discriminante, indicando as variáveis que melhor discriminam os respondentes de cursos presenciais e a distância pelo teste Lambda de Wilks, pelo teste F e pela significância de cada variável no modelo pelo nível de $1 \%$.

Ressalta-se que a função discriminante apresentou uma correlação canônica de 0,57 , indicando que $32,30 \%$ do total da variância podem ser explicados pelo modelo a um grau de significância de $1 \%$. Ademais, cabe ressaltar que $78,3 \%$ dos casos originais foram classificados corretamente, indicando um alto percentual de classificação quanto ao agrupamento dos respondentes. 
Tabela 4: Variáveis que melhor discriminam os grupos pela análise discriminante

\begin{tabular}{|l|c|c|c|}
\hline \multirow{2}{*}{\multicolumn{1}{|c|}{ Variáveis }} & \multicolumn{2}{c|}{ Lambda de Wilks } \\
\cline { 2 - 4 } & \multirow{2}{*}{ Estatística } & \multicolumn{2}{c|}{ F exato } \\
\cline { 3 - 4 } & & Estatística. & \multicolumn{1}{c|}{ Sig. } \\
\hline Capacidade de lidar com incertezas e dúvidas & 0,677 & 13,905 & 0,000 \\
\hline Capacidade empreendedora & 0,699 & 14,682 & 0,000 \\
\hline Visão de mundo ampla e global & 0,715 & 16,440 & 0,000 \\
\hline Domínio de novos conhecimentos técnicos ligados à profissão & 0,751 & 17,188 & 0,000 \\
\hline Capacidade de interp. textos, gráficos, símbolos e números & 0,811 & 16,145 & 0,000 \\
\hline Capacidade de cooperação e trabalho em equipe & 0,863 & 16,562 & 0,000 \\
\hline Capacidade de inovação & 0,944 & 12,516 & 0,000 \\
\hline
\end{tabular}

Os resultados da função discriminante indicam que os alunos de cursos presenciais tendem a apresentar maiores médias nas competências relacionadas a capacidade de interpretar textos, gráficos, símbolos e números; capacidade de cooperação e trabalho em equipe. Já os alunos de cursos a distância tendem a apresentar maiores médias nas competências relacionadas a capacidade de lidar com incertezas e dúvidas; visão de mundo ampla e global; domínio de novos conhecimentos técnicos ligados à profissão e capacidade de inovação, conforme demonstrado na Tabela 5

Tabela 5: Comparativo entre competências desenvolvidas modalidade presencial e a distância

\begin{tabular}{|c|c|c|}
\hline Competências & Presenciais & a distância \\
\hline Capacidade de interp. textos, gráficos, símbolos e números & 8,30 & 7,40 \\
\hline Capacidade de cooperação e trabalho em equipe & 8,85 & 8,04 \\
\hline Capacidade de lidar com incertezas e dúvidas & 6,67 & 7,40 \\
\hline Visão de mundo ampla e global & 7,16 & 8,04 \\
\hline Domínio de novos conhecimentos técnicos ligados à profissão & 6,90 & 7,84 \\
\hline Capacidade de inovação & 6,35 & 7,38 \\
\hline
\end{tabular}

Fonte: Dados da pesquisa

Os resultados da função discriminante indicam que os alunos de cursos presenciais tendem a apresentar maiores médias nas competências relacionadas a capacidade de interpretar textos, gráficos, símbolos e números; capacidade de cooperação e trabalho em equipe. Já os alunos de cursos a distância tendem a apresentar maiores médias nas competências relacionadas a capacidade de lidar com incertezas e dúvidas; visão de mundo ampla e global; domínio de novos conhecimentos técnicos ligados à profissão e capacidade de inovação, conforme demonstrado na Tabela 5

\section{CONCLUSÕES}

Após a análise dos resultados obtidos em cada grupo pesquisado (alunos de educação presencial e à distância), identificaram-se algumas particularidades que os distinguem entre si, principalmente quando se refere ao perfil demográfico.

Os alunos dos cursos a distância possuem idade média maior do que os alunos dos cursos presenciais pesquisados, assim como afirmado por Moore e Kearsley (2011) e Nunes (2009), sendo também a maioria casada, ao contrário dos alunos presenciais, em que a maioria é solteira. Sobre o local onde cursaram escola pública, a maioria dos alunos a distância cursou em instituições públicas, ao contrário 
dos alunos presenciais que cursaram em instituição particular. Nesse sentido, percebe-se claramente que essas duas modalidade educacionais, apesar de possuírem o mesmo objetivo, ou seja, capacitar e profissionalizar pessoas para o mercado de trabalho, ainda possuem cursistas com perfis diferenciados, o que de certa forma, acarreta um resultado diferente em relação às competências desenvolvidas pelos alunos, como identificado nesse estudo.

Sobre a experiência profissional dos pesquisados na área administrativa, identificou-se que os alunos dos cursos à distância possuem maior tempo de experiência na área em detrimento dos alunos dos cursos presenciais, podendo esse resultado ser explicado pelo fator idade. A escolha pelo curso superior em Administração também foi algo diferente na percepção dos grupos. Os alunos à distância relataram ter escolhido o curso por ascensão profissional, já que muitos trabalham na área administrativa. Já os alunos dos cursos presenciais relataram ter sido por interesse pela área administrativa. Assim, destaca-se que os alunos à distância por já estarem inseridos no mercado de trabalho procuraram algo a mais na profissão (mudança de emprego, aumento de salário, por exemplo) do que pelo fato de terem interesse pela área de formação do respectivo curso. Relativo ao setor de atuação, a maioria dos alunos à distância atuam no setor público, ao contrário dos alunos presenciais que a maioria atua nos setores de serviço e indústria, o que também os fazem desenvolver competências diferentes uns dos outros.

No que tange às competências gerais desenvolvidas ao longo das atividades de formação acadêmica, identificou-se que os alunos da educação à distância tiveram o Índice de Competências Gerais Desenvolvidas (ICGD) levemente superior se comparado à percepção dos respondentes dos cursos presenciais $(7,62$, e 7,34 respectivamente), o que pode ser comparado com a qualidade de cursos à distância e presencial, em que, quando possível a comparação entre cursos, alunos de cursos a distância tiveram desempenho melhor que dos alunos de educação presencial (INEP/ENADE, 2013). Isso pode ser explicado, em partes, pelo grau de maturidade dos alunos dos cursos a distância e por eles já estarem inseridos no mercado de trabalho a mais tempo em detrimento dos alunos dos cursos presenciais pesquisados.

Os resultados da função discriminante indicam que os alunos de cursos presenciais tendem a apresentar maiores médias nas competências relacionadas a capacidade de interpretar textos, gráficos, símbolos e números, pois admite-se que por eles serem auxiliados presencialmente pela figura do professor, pode facilitar a melhor compreensão e interpretação de conteúdos da área de exatas; capacidade de cooperação e trabalho em equipe, visto que a interação entre eles ocorre com frequência e presencialmente e, não somente por meio eletrônico, o que facilita a troca de experiências e a cooperação entre si.

Já os alunos de cursos a distância tendem a apresentar maiores médias nas competências relacionadas a visão de mundo ampla e global; capacidade de lidar com incertezas e dúvidas; domínio de novos conhecimentos técnicos ligados à profissão, pois percebe-se que eles têm um tempo médio considerável de atuação na área de formação se comparado aos alunos de cursos presenciais, assim desenvolvem com maior facilidade os conhecimentos relativos à sua profissão. Além disso, percebe-se que apresentam maiores médias em relação a capacidade de inovação por terem que criar seu próprio espaço de aprendizado e conhecimento (Belcheir \& Cucek, 2002; Kerr, Rynearson \& Kerr, 2006).

Complementarmente, ressalta-se que apesar de ser um mesmo curso pesquisado (Graduação em Administração), as distintas modalidades educacionais apresentam diferenças no que tange às competências desenvolvidas pelos alunos. Os alunos do curso da modalidade presencial parecem estar mais ligados a questões desenvolvidas no âmbito teórico, o que de fato é justificado por terem poucos 
alunos inseridos no mercado de trabalho e por ainda não apresentarem visão crítica entre a teoria ministrada em sala de aula e as ações práticas que acontecem dentro das empresas e no mercado em geral. Já para os alunos da modalidade a distância, a prática desenvolvida no mercado trabalho é algo que possivelmente influencia o desenvolvimento de competências e que de fato os fazem desenvolver muito mais habilidades relacionadas a capacidade de criação e inovação, domínios técnicos ligados à profissão, aplicação de novos conceitos no ambiente de trabalho, dentre outros.

Desta forma, pode-se inserir que a formação prévia ou prática de mercado influenciam no desenvolvimento de competências no meio acadêmico. Isso nos admite a crer que as Instituições de ensino precisam adaptar sua metodologia de ensino e conteúdos ministrados de acordo com o perfil dos alunos, pois as competências desenvolvidas se originam muito mais da experiência dos alunos do que dos conteúdos propriamente ministrados. Há de se ressaltar que as decisões aferidas nesse estudo requerem algumas limitações que devem ser consideradas na utilização dos resultados da pesquisa.

Os alunos pesquisados dos cursos de Administração à distância e presencial, não pertenciam às mesmas IPES, fato este que deve ser considerado quando se compara as competências desenvolvidas em cada modalidade de educação. Contudo, optou-se por compará-los por pertencerem ao curso de Administração de Instituições Públicas de Ensino Superior.

Diante das limitações do estudo, algumas recomendações para estudos futuros podem ser descritas, como por exemplo, pesquisar as competências desenvolvidas por alunos de um mesmo curso como Contabilidade e Economia - áreas afins à Administração, atuantes no mesmo período de mesmas IPES e nas duas modalidades educacionais, a fim de se obter uma comparação mais fiel das competências desenvolvidas entre cursos presenciais e à distância.

Recomenda-se também comparar as competências específicas inerentes de cursos superiores nas duas modalidades de educação, com o intuito de verificar se há diferenças significativas entre as modalidades educacionais e propor soluções para readequação do processo didático-pedagógico de ambos os cursos, a fim de minimizar as lacunas existentes entre eles ao procurar desenvolver melhor aquelas competências que estejam insuficientes, a partir das percepções dos alunos, no intuito de garantir uma vida sustentável, seja no âmbito pessoal, social e profissional. 


\section{REFERÊNCIAS}

Baartman, L., \& Ruijs, L. (2011). Comparing students' perceived and actual competence in higher vocational education. Assessment \& Evaluation in Higher Education, 36(4), 385-398.

Barth, M., Godemann, J., Rieckmann, M., \& Stoltenberg, U. (2007). Developing key competencies for sustainable development in higher education. International Journal of Sustainability in Higher Education, 8(4), 416-430.

Belcheir, M. J. \& Cucek, M. (2002). Faculty Perceptions of Teaching Distance Education Courses. Report Research, 2. Idaho: USA.

Beneitone, P., Esquetini, C., González, J., Maletá, M. M., Siufi, G., \& Wagenaar, R. (2007). Reflections on and outlook for Higher Education in Latin America. Bilbao: Universidad de Deusto.

Bleiklie, I. (2005). Organizing higher education in a knowledge society. Higher Education, 49, 31-59.

Boyatzis, R. E. (1982). The competent manager: A model for effective performance. New York: John Wiley \& Sons.

Brasil, V. L. B. (2009) Competências profissionais e organizacionais: Um estudo prospectivo entre os anos de 2004 e 2014. Revista de Estudos de Administração, 9(18), 159-186.

Chizzotti, A., \& Casali, A. (2012). O paradigma curricular europeu das competências. Cadernos de História da Educação, $11,13-30$.

Fleury, M. T. L.; Fleury, A. C. C. (2001). Construindo o Conceito de Competência. RAC, [Edição Especial], 183-196.

Gilomen, H. (2003). Conclusions and Next Steps. In: D. S. Rychen, L. H., Salganik, \& M. E. Mclaughlin (Org.), Contributions to the Second DeSeCo Symposium, (pp. 203-208). Swiss Federal Statistical Office. Retrieved from http:www.oecd.org/ edu/skills-beyond-school/ 41529505.pdf.

Godoy, A. S., \& Antonello, C. S. (2009). Competências individuais adquiridas durante os anos de graduação de alunos do Curso de Administração de Empresas. Revista de Ciências da Administração, 11(23), 157-191.

Hair, F. Jr., Anderson, R. E., Tatham, R. L., Black, W. C., \& Babin, B.J. (2009). Análise Multivariada de Dados (6a ed.). Porto Alegre: Bookman.

Holmes, G., \& Hooper, N. (2000). Core competence and education. Higher Education, 40, 247-258.

Huh, S., Jongdae, J., Lee, K. J. \& Yoo, S. (2010). Differential effects of student characteristics on performance: online vis-a-vis offline accounting courses. Academy of Educational Leadership Journal, 14(4),1-9.

Instituto Nacional de Estudos e Pesquisas Educacionais Anísio Teixeira. Portal INEP/ENADE. (2013). Recuperado em 09 de dezembro de 2013, de http://portal.inep.gov.br/enade 
Istance, D. (2003). Schooling and Lifelong Learning: insights from OECD analyses. European Journal of Education, 38(1), $85-98$.

Kerr, M. S., Rynearson, K. \& Kerr, M. C. (2006). Student characteristics for online learning success. Internet and Higher Education. 9, 91-105.

Le Boterf, G. (2003). Desenvolvendo a competência dos profissionais. Porto Alegre: Artmed.

Lozano, J. F., Boni, A., Peris, J., \& Hueso, A. (2012). Competencies in higher education: a critical analysis from the capabilities approach. Journal of Philosophy of Education, 46(1), 132-147.

Mcclelland, D. C. (1973). Testing for Competence Rather Than for "Intelligence". American Psychologist, 1-14. Retrieved from http:www.lichaoping.com/wp-content /ap7301001.pdf.

Mello, S. L., Melo, J. S. M. Jr., \& Mattar, F. N. (2011). Perfil, formação, atuação e oportunidades de trabalho do administrador: pesquisa nacional (5a ed). Brasília: CFA.

Moore. M. G. \& Kearsley, G. (2011). Educacao a distância: Uma visão Integrada. São Paulo: Cengage Learning, 1-14.

Mulder, M., Gulikers, J., Biemans, H., \& Wesselink, R. (2009). The new competence concept in higher education: error or enrichment? Journal of European Industrial Training, 33(8/9), 755-770.

Nogueira, A. J. F. M., Bastos, F. C. (2012). Formação em Administração: O gap de competências entre alunos e professores. REGE, 19(2), 221-238.

Nunes, I. B. (2009). A história da EAD no Brasil. In: F. M. Litto \& M. Formiga (Org.). Educação a Distância - o estado da arte. São Paulo: Pearson Education do Brasil, 02-08.

Nunes, S. C. (2010). O ensino em administração: análise à luz da abordagem das competências. Revista de Ciências da Administração, 12(28), 198-223.

Odelius, C. C., \& Sena, A. C. (2009). Atuação em grupos de pesquisa: competências e processos de aprendizagem. Revista de Administração FACES Journal, 8(4), 13-31.

Organisation for Economic Co-operation and Development [OECD]. (2001). Definition and Selection of Competencies: Theoretical and Conceptual Foundations (DeSeCo), Background Paper. Retrieved from http://www.oecd.org /education/ skills-beyond-school/41529556.pdf.

Ouane, A. (2003). Defining and selecting key competencies in lifelong learning. In: In: D. S. Rychen, L. H., Salganik, \& M. E. Mclaughlin (Org.), Contributions to the Second DeSeCo Symposium, (pp. 203-208). Swiss Federal Statistical Office. Retrieved from http:www.oecd. org/edu/skills-beyond-school/41529505.pdf> acesso em 10 de Maio de 2013.

Perrenoud, P. (2001). Ensinar: agir na urgência, decidir na incerteza (2a ed.), Porto Alegre: Artmed. 
Pons, J. (2010). Universidad y sociedad del conocimiento. Las competencias informacionales y digitales. RUSC, 7(2), 6-16.

Rychen, D. S., \& Salganik, L. H. (2005). The definition and selection of key competencies: Executive summary. OECD. Retrieved from http://www.oecd.org/pisa/ 35070367.pdf.

Sant'anna, A. S. (2002). Competências individuais requeridas, Modernidade organizacional e satisfação no trabalho: Uma análise de organizações mineiras sob a ótica de profissionais da área de administração (Tese de doutorado). Universidade Federal de Minas Gerais, Belo Horizonte, MG, Brasil.

Souza, D. L. (2014) Desenvolvimento de competências e ambiente acadêmico: Um estudo em cursos de Administração (Dissertação de Mestrado). Universidade Federal de Lavras, Lavras, MG, Brasil.

Souza, D. L., Corrêa, R. D. S., Sousa, J. S., \& Zambalde, A. L. (2013, setembro). Formação Acadêmica e Gestão de Competências: Avaliando o Papel das Instituições de Ensino no Desenvolvimento de "Competências Requeridas". Anais do Encontro da Associação Nacional dos Programas de Pós-Graduação em Administração, Rio de Janeiro, RJ, Brasil.

Spencer, L. M, \& Spencer, S. (1993). Competence at work. New York: John Wiley, 1993.

Taylor-Powell, E, \& Hermann, C. (2000). Collecting evaluation data: surveys. Madison: University of Wisconsin-Extension. Retrieved from http://www.caes.uga.edu/unit/abo/pda/resources/documents/5CollectingEvaluationData_Surveys.pdf.

Tudorescu, N., Zaharia, C., Zaharia, G.C. \& Zaharia, I. (2010). Human Capital Accumulation and Long-Run Economic Growth. Economics, Management, and Financial Markets, 5(4), 250-255.

Valimaa, J., \& Hoffman, D. (2008). Knowledge society discourse and higher education. High Educ, 56, 265-285.

Vergara, S. C. (2005). Métodos de Pesquisa em Administração. São Paulo: Atlas.

Weinert, F. E. (1999). Concepts of competence. Contribution within the OCED-Project Definition and Section of Competencies: Theoretical and Conceptual Foundations (DeSeCo). Neuchâtel: Bundesamt für Statistik.

Young, M. (2010). Alternative Educational Futures for a Knowledge Society. European Educational Research Journal, 9(1), 1-12.

Zarifian, P. (2001). Objetivo e competência: por uma nova lógica. São Paulo: Atlas. 